\title{
Linguo-cultural competence as a cornerstone of translators' performance in the domain of intercultural business communication
}

\author{
Elena N. Malyuga - Alex Krouglov - Barry Tomalin
}

DOI: 10.18355/XL.2018.11.02.46

\begin{abstract}
Acknowledging language as an integral element of a sociocultural community highlights some sensitive areas in the realm of translation studies. Since the translator acts as a mediator between two unique cultures, the efficiency of cross-cultural interaction appears to be largely dependent on the quality of such intermediacy. The present paper aims to examine this culturally determined specificity of translation activity and consider lingua-cultural competence as a cornerstone of translators' performance. The authors also contemplate the opposition of 'accuracy' vs 'readability' as a stumbling block for translator's activity, and draw up a model of the lingua-cultural competence of translators specialising in intercultural business communication. Inferences made in the study rely on the data obtained from a questionnaire distributed among tutors and lecturers employed in higher educational institutions and involved in specialised translation training. The data collected were analysed based on statistical analysis that helped identify the importance of each separate skill incorporated in the lingua-cultural competence for the training of student translators specialising in intercultural business communication. This evidence was further utilised to elaborate on a set of methodological guidelines capable of developing the lingua-cultural competence of student translators specialising in intercultural business communication.
\end{abstract}

Key words: specialised translation, intercultural business communication, linguacultural competence, translation training, translation accuracy, translation equivalence

\section{Introduction}

Intercultural interaction invariably implies that communicating entities appear as subjects of culture, representatives of a certain sociocultural community. Culture functions as a set of material and spiritual values of society, comprising a variety of historical, social, and psychological aspects of the enthnic group, its traditions, attitudes, values, institutions, behaviour, lifestyle, living conditions - in other words, all dimensions of its existence and consciousness, including its language (Breus, 2000). Therefore, the translator appears to operate as a point of contact between the two cultures, an agent guiding the process of communication, and this function happens to be especially important in the context of business interaction (Maialen, 2017). Consequently, there is a wide range of competences for translators to master.

In the present paper, it is argued that the efficiency of the end product of translation efforts does not rely on linguistic competence and cultural competence as two individual types of professional expertise, but feeds upon a combination of the two, i.e. lingua-cultural competence.

This hypothesis shall herein be explained based on another assumption suggesting that efficient translation is contingent upon translators' lingua-cultural knowledge which implies not only mastery of the lexis and syntax of the source and target languages, but also awareness of 'the way of life and its manifestations that are peculiar to a community that uses a particular language as its means of expression' (Gill and Guzman, 2011; Millan, Bartrina, 2013).

It is also argued that the processes of globalisation and Europeanisation have had a significant impact on new developments in the field of specialised translation. It 
is a paradox that even though we witness the spread of English in various cultures and specialised fields, the demand for specialised translations continues to grow significantly in various language combinations (the pair of languages to be translated from one into the other) (Gotti, Sarcevic, 2006).

Another hypothesis underlying the present study states that one of the vital issues in training specialised translation is associated with the problem of 'dual loyalty' (Schweitzer, 1988) that has to do with translator's aspiration to give credit to both the original text (thus ensuring accuracy) and the target text (thus ensuring readability).

The scope of the present research is further focused, as the authors narrow it down to specialised translation viewed as part of intercultural business communication (IBC, hereafter), and consider a model of the lingua-cultural competence of translators specialising in IBC.

Therefore, the study aims to:

- analyse specialised translation in terms of its association with the domain of IBC;

- $\quad$ examine culturally determined specificity of translation activity;

- consider lingua-cultural competence as a cornerstone of translators' performance;

- $\quad$ give consideration to the opposition of 'accuracy' vs 'readability' as a stumbling block for translator's activity; and

- draw up a model of the lingua-cultural competence of translators specialising in IBC.

In order to proceed with the outlined argument, it is imperative to address the notion of specialised translation, which can be defined as the process of crosslingual and intercultural communication, which generates a secondary text, elaborated on the basis of a focused and multilateral analysis of the primary verbal text on a narrow professional subject matter (House, 2009). This process involves the transfer of the communicative effect of the primary text, which is partially modified due to the differences between the two languages, two cultures, and two communicative situations. Specialised translation as a form of intercultural communication requires special training and skills and calls for mastery of both foreign and native languages and cultures (Parlakkilic, 2016). This definition, albeit rather bulky, reflects the multidimensional and multifunctional nature of specialised translation, highlights the way it differs from other forms of crosslingual interaction, accentuates its complex and contradictory nature and, most importantly, its fundamental paradox - the pursuance of accuracy and commitment to embrace and reflect cultural norms and standards.

The distinctive nature of national, linguistic worldviews and multiculturalism act as obstacles to international rapport and this is why awareness of other peoples' cultures is one of the key social functions of translation. A translator perceives and interprets foreign texts from the perspective of foreign linguistic and cultural settings to further shift to his or her native linguistic and sociocultural codes (Katan, 2009).

In this respect, language is being interpreted as an integral sociocultural entity reflecting the features of a certain ethnic group as a carrier of a specific culture, and outlining this culture as a distinctive heritage different from other civilisations. This peculiarity of language is all the more crucial when it comes to IBC.

IBC is a complex process associated with the establishment, maintenance, and development of contact between people of various nationalities in the professional sphere. This process occurs in the context of divergent ethnic and cultural attitudes, rules, and standards, while its ultimate goal lies in reaching business agreements between the parties concerned (Chaney and Martin, 2013). 
IBC is an integral part of people's professional culture. Proficiency in this sphere helps ensure efficient cooperation between business partners. Being familiar with sociocultural factors helps eliminate some typical errors and misunderstandings arising in the course of IBC. This is why the study of IBC is closely related to the study of multicultural and multilingual reality (Moll, 2012).

IBC as a system incorporating a number of variables, which include communication between participants; the relationship between the communicating parties; the form of business communication (oral or written); the channels of business communication (face-to-face interaction or correspondence); instruments of business communication (letters, contracts, agreements, negotiations, consultations, meetings, etc.); the communicative strategies and tactics used; context, etc. (Tomalin and Nicks, 2014).

Thus, IBC is an art that needs to be mastered in order to overcome intercultural 'shock' and reach an understanding with the foreign business partner. IBC is not only defined by social factors alone but is also contingent on people's stereotypes and cultural patterns of behaviour (Malyuga, 2016). Using a foreign language, business partners accumulate cultural knowledge and learn to understand the mentality of people belonging to different lingua-cultural communities (Ponomarenko, Malyuga, 2015).

That being said, it can be positively stated that efficient and competent specialised translation is an especially sought-after service in the sphere of IBC. Competent experts in the field of specialised translation must be familiar with: ethical and moral standards of conduct adopted in the community, as well as models of social settings, typical interaction scenarios; key features of formal, neutral and informal communication registers; rules of international etiquette applied in various situations of IBC, etc. (Munday, 2012). A competent translator should also be able to:

- navigate the system of universal values;

- take into account the standards accepted within various social, national, religious, professional communities and groups;

- $\quad$ express ideas, making adequate use of various language means and appropriate terminology in order to provide accurate translation and highlight relevant information;

- $\quad$ simulate possible communicative scenarios;

- control the state of anxiety to cope with both psychological and professional pressure (Chen, 2016).

Thus, the background knowledge required to ensure efficient translation services in the sphere of IBC appears to be rather extensive, inasmuch as it covers a wide range of both universal and field-specific expertise.

In line with the above, it should be noted that a worldview is reflected differently in various languages, and the form of its expression is manifested in national features, habits, customs, and traditions, generated under the influence of living conditions and the peculiarities of historical development. Therefore, competent translation will call for full-fledged knowledge of both peoples' cultural and historical background.

\section{Translation and cultural knowledge}

German philosopher Schleiermacher (1999) suggested that translation as a process was at all times associated with comprehension, reasoning, and communication, with a special emphasis on comprehension due to its most prominent ties with translation. Pursuant to Schleiermacher's definition, translation is an act of perception, inasmuch as the key objective of translation efforts lies in making the source text understandable to the reader (Schleiermacher, 1999). At the same time, any source text to be translated presents a very intricate material. All of its features (such as its form and content, its goal and communicative functions, as well as its 
aesthetic value) are shaped based on a broad spectrum of concurrent factors that define the author's choices in the process of text generation. These factors and choices some way or other accrue from culture, which at all times maintains a very intimate relationship with language, and it is this liaison between culture and language that defines the overwhelming value of translators' cultural knowledge (Tonkin and Frank, 2010).

The very meaning of language is unraveled through the comprehension of the historic, scientific, artistic, and aesthetic background of the corresponding community, which adds another dimension to the scope of cultural knowledge to be acquired by the translator. From this perspective, target text production appears to depend not only on the translator's intellectual merits but also on his or her open-mindedness.

Therefore, linguistic understanding in the process of translation can only be viewed as a 'puzzle piece' that needs to be complemented by cultural insight. Linguistic knowledge coupled with cultural awareness should be considered a bedrock of translators' expertise, which lies in the ability to use compatible linguistic means to express culturally marked conventions accepted in both linguacultures (Malyuga, Ponomarenko, 2015).

Importantly, regional and dialectal varieties of the same language also present an issue of interest in the domain of translation studies, for they also bear testament to the intricate culturally marked peculiarities reflected in the languages used by different groups (Malyuga, Tomalin, 2014).

The perculiarity of varieties of the same language can be explored through the example of American and British English spoken in the USA and the UK respectively. As Commager (1974) says, the spirit of conservatism deeply penetrated the English national character. Commager (1974) highlights four features: conservatism, compliance with laws, practicality, and love for the motherland. The author emphasises that the British are law-abiding people, considering that not only the government but also people benefit from this compliance with the law. Americans, on the other hand, are a nation of practical and pragmatic people who appreciate their freedom and look for diversity. They believe that freedom can be guaranteed only by their material wealth, and that is why they stress the importance of materialism and self-reliance (Commager, 1974). Just as the USA and the UK are distinguised by their own nation-specific features, the varieties of English used by Americans and the British are also characterised by some distinctive features, which set them apart and which need to be addressed and carefully studied by translators. These include differences in the designation of notions related to all sorts of fields, such as education, politics, business and finance, transport, time and weight measurements, as well as notions pertaining to the domain of politically correct nominations, etc.

Considering the two main varieties of English (American and British English), one can observe both a continuous interaction and a constant struggle between them. The utmost rapprochement between the two Englishes becomes evident whenever they are studied against the backdrop of specific genres, such as, for example, business communication (Malyuga et al., 2016).

Another important factor to consider is the tendency of globalisation and, particularly, Europeanisation of cultures and languages. The concept of Europeanisation has been studied in relation to changes in politics, fundamental principles, liberal democracy, economy, infrastructure, legal systems, education and in many other spheres. Europeanisation impacts languages and cultures and therefore affects translation processes. There are various definitions of Europeanisation but it can essentially be defined as 'domestic change caused by European integration' (Krouglov, 2015). Europeanisation is often considered in relation to three main areas: legal obligations mostly in political and economic spheres, 'objective changes in economic structures and in the interests of individuals as a result of' European

XLinguae, Volume 11, Issue 2, April 2018, ISSN 1337-8384, eISSN 2453-711X 
integration, and, finally, 'subjective changes in the beliefs, expectations and identity of the individual' (Emerson, Noutcheva, 2004). These three main areas have a significant impact on discourse, produce changes in languages and corpora and eventually affect translation processes. The European aspect affects languages and their corpora and should be considered in respect of a wide range of processes, institutions, and fields. This process usually goes beyond the geographical borders of the European Union (Emerson and Noutcheva, 2004).

That being said, it should be noted that an efficient and adequate intercultural communication is only possible provided that communicating entities belonging to different cultures and, hence, making use of different languages are aware of their dissimilarities, globalisation tendencies and are ready and willing to embrace them (Pym, 2012). And this is where it is important to turn to the translator acting as a mediator for both parties, explaining to them the main rules of conduct and illuminating national customs. The translator will have to choose equivalent linguistic counterparts to depict various phenomena and, thus, mitigate cultural differences.

Most translators are marked by a prevailing language or culture. This language and this culture dominate other languages and cultures the translator encounters in his or her activity. In the course of translation, both languages are present in the speech acts produced, and both are functioning simultaneously. And so, the facts and meanings enclosed in speech acts generated in another language and embedded in the source text, are being perceived and interpreted through the prism of the dominating language and culture to be further enclosed in the target text (Bassnett, 2013).

The prevailing philosophy is that, all things considered, the ultimate objective any competent translator should commit to actually lies in almost 'mathematical' (i.e. accurate, scrupulous) reproduction of the information in the target language. While this is obviously true, such 'accuracy' might be (and more often than not is) fraught with controversy and risks to the end product. Setting accuracy and readability against one another, which of the two functional aspects should be considered as a higher priority?

Naturally, this binary opposition of 'accuracy' vs 'readability' might well be resolved if only there was a way to combine the two aspects, merging them into a single, steadfast, and efficient signpost to guide the translators. The question that remains is how to address this challenge, and the answer to that lies in the development of lingua-cultural competence.

\section{Lingua-cultural competence of a translator}

As a mediator of communicative interaction, the translator is faced with culturally marked data of a rather extensive scope. Communicative interaction reflects a wide range of national and cultural values, which define the patterns of people's communicative behaviour. As culturally marked meanings are viewed as an essential component of translation, it is thus important to address the issue of lingua-cultural competence as a set of knowledge and skills translators need (or rather are obliged) to develop.

This kind of expertise reflects the translator's professional efficiency and comprises a set of skills required to ensure adequate translation of culturally marked meanings. Lingua-cultural competence is structurally divided into three key components: discourse skills, strategic skills, and rhetorical skills (Munday, 2012).

Translator's discourse skills are a combination of knowledge, verbal and communicative skills that underlie his or her ability to structure a semantic entity out of separate utterances, thus providing for the efficient compositional organisation of the output text. 
Translator's strategic skills include knowledge, as well as verbal and communicative skills, facilitating the elective use of language means to ensure efficient structural-semantic organisation of the output text.

Translator's rhetorical skills are associated with the effective use of adequate linguistic means and construction of efficient speech acts that help achieve the communicative effect required and ensure efficient rhetoric organisation of the output text (Munday, 2012).

Thus, discourse, strategic, and rhetorical skills of a translator are associated with his or her ability to ensure compositional, structural-semantic, and rhetorical organisation of the output text. Therefore, emphasis may be placed on the compositional, structural-semantic, and rhetorical accuracy of the translation.

Compositional accuracy relies on the following communicative skills: (a) ability to recognise the peculiarities of logical and compositional organisation of the source text and ensure logical and compositional accuracy of the target text; (b) ability to identify linking elements in the source text and find adequate counterparts in the target language; (c) ability to define the boundaries of micro- and macro-themes in the source text and ensure their adequate representation in the target text.

Structural-semantic accuracy relies on the following communicative skills: (a) ability to interpret cultural semantics of lexical units of the source text and deliver their meaning in the target language; (b) ability to translate cultural semantics of grammatical units of the source text and deliver their meaning in the target language; (c) ability to identify cultural peculiarities of thematic and rhematic organisation of the source text and ensure adequate thematic and rhematic organisation of the target text.

Rhetorical accuracy relies on the following communicative skills: (a) ability to recognise communicative strategies used in the source language and ensure accurate build-up of communicative strategies in the target language; (b) ability to recognise speech tactics implemented as part of communicative strategies of the source text and provide for their accurate representation in the target language; (c) ability to analyse the stylistic composition of the source text and ensure adequate representation of appropriate stylistic means in the target text.

Hence, the model of the lingua-cultural competence of a translator can be presented as follows (Figure 1).

\section{Lingua-cultural competence of a translator}

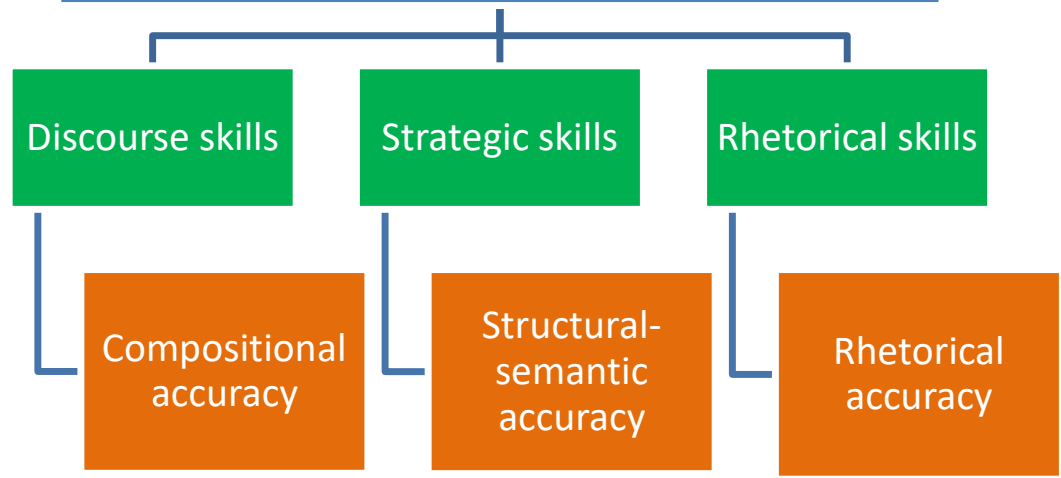

XLinguae, Volume 11, Issue 2, April 2018, ISSN 1337-8384, eISSN 2453-711X 
Figure 1. The model of the lingua-cultural competence of a translator

\section{Methodology}

Consistent with the objectives outlined in the introduction to the paper, the study sets out to highlight the role of the lingua-cultural competence in ensuring adequate and accurate transfer of information into the target language in the course of translation of intercultural business discourse. A challenging task in this respect would be evaluating it in terms of practical importance for future translators specialising in IBC, and seeing that there is no rock-solid and overwhelmingly objective technique to do that (as, obviously, competences as such imply uncertainty in terms of level of mastery required, assessment techniques applied, and objective importance attached), one might conclude that the most expedient inferences could be made through surveying those involved in the process in the line of profession. The survey used in the study relied on the data collected by tutors, teachers, and lecturers employed in higher educational institutions in Russia, the UK and the USA and involved in specialised translation training. The answers gathered from the total of 79 respondents were considered sufficient for the purposes of the survey, as the data obtained allowed to generate consistent and well-defined inferences.

The respondents involved in the survey represented three countries and six affiliations (Table 1).

\begin{tabular}{|c|c|c|c|}
\hline Country & Affiliation & Description & $\begin{array}{c}\text { Total } \\
\text { respondents } \\
\text { involved }\end{array}$ \\
\hline Russia & $\begin{array}{l}\text { Peoples' Friendship } \\
\text { University of Russia } \\
\text { (RUDN University) } \\
\text { Moscow State Institute of } \\
\text { International Relations } \\
\text { (MGIMO University) of } \\
\text { the Ministry of Foreign } \\
\text { Affairs of Russia }\end{array}$ & $\begin{array}{l}\text { The Dpt of Foreign } \\
\text { Languages (Faculty of } \\
\text { Economics) has been } \\
\text { teaching professional } \\
\text { and business } \\
\text { communication and } \\
\text { specialised translation } \\
\text { to BA and MA students } \\
\text { for about twenty years } \\
\text { RUDN University's } \\
\text { partner }\end{array}$ & 36 \\
\hline UK & $\begin{array}{l}\text { London Metropolitan } \\
\text { University } \\
\text { Loughborough University }\end{array}$ & $\begin{array}{l}\text { RUDN University's BA } \\
\text { and MA double diploma } \\
\text { programme partner }\end{array}$ & 20 \\
\hline USA & $\begin{array}{l}\text { Northern Kentucky } \\
\text { University }\end{array}$ & $\begin{array}{l}\text { RUDN University's } \\
\text { partner extensively } \\
\text { covering Russian } \\
\text { language studies and } \\
\text { English-Russian } \\
\text { translation studies }\end{array}$ & 23 \\
\hline
\end{tabular}

Table 1. Number and affiliation of Russian, British and American respondents involved in the survey 
All respondents participating in the survey teach courses of translation or business and professional communication.

The questionnaire designed for the survey was intended to gather evaluative responses with ranks ranging from 1 to 10 (with 1 referring to least important skill, and 10 referring to the most important skill) and subject to objective justification by respondents (Table 2).

\begin{tabular}{|c|c|c|c|}
\hline No. & Skill & $\begin{array}{c}\text { Level of significance } \\
\text { (please check whichever } \\
\text { appears appropriate based } \\
\text { on your professional } \\
\text { expertise) }\end{array}$ & $\begin{array}{c}\text { Comments } \\
\text { (please justify } \\
\text { skill appraisal } \\
\text { provided, } \\
\text { furnishing both } \\
\text { theoretical and } \\
\text { practical } \\
\text { grounding) }\end{array}$ \\
\hline 1. & $\begin{array}{l}\text { Ability to recognise the } \\
\text { peculiarities of logical and } \\
\text { compositional organisation of } \\
\text { the source text and ensure } \\
\text { logical and compositional } \\
\text { accuracy of the target text }\end{array}$ & (1) (2) (3) (4) (5) (6) (7) (8) (9) (10) & \\
\hline 2. & $\begin{array}{l}\text { Ability to identify linking } \\
\text { elements in the source text and } \\
\text { find adequate counterparts in } \\
\text { the target language }\end{array}$ & (1) (2) (3) (4) (5) (6) (7) (8) (9) (10) & \\
\hline 3. & $\begin{array}{l}\text { Ability to define the } \\
\text { boundaries of micro- and } \\
\text { macro-themes in the source } \\
\text { text and ensure their adequate } \\
\text { representation in the target } \\
\text { text }\end{array}$ & (1) (2) (3) (4) (5) (6) (7) (8) (9) (10) & \\
\hline 4. & $\begin{array}{l}\text { Ability to interpret cultural } \\
\text { semantics of lexical units of } \\
\text { the source text and deliver } \\
\text { their meaning in the target } \\
\text { language }\end{array}$ & (1) (2) (3) (4) (5) (6) (7) (8) (9) (10) & \\
\hline 5. & $\begin{array}{l}\text { Ability to translate cultural } \\
\text { semantics of grammatical } \\
\text { units of the source text and } \\
\text { deliver their meaning in the } \\
\text { target language }\end{array}$ & (1) (2) (3) (4) (5) (6) (7) (8) (9) (10) & \\
\hline 6. & $\begin{array}{l}\text { Ability to identify cultural } \\
\text { peculiarities of thematic and } \\
\text { rhematic organisation of the } \\
\text { source text and ensure } \\
\text { adequate thematic and } \\
\text { rhematic organisation of the } \\
\text { target text }\end{array}$ & (1) (2) (3) (4) (5) (6) (7) (8) (9) (10) & \\
\hline 7. & $\begin{array}{l}\text { Ability to recognise } \\
\text { communicative strategies used } \\
\text { in the source language and }\end{array}$ & (1) (2) (3) (4) (5) (6) (7) (8) (9) (10) & \\
\hline
\end{tabular}

XLinguae, Volume 11, Issue 2, April 2018, ISSN 1337-8384, eISSN 2453-711X 


\begin{tabular}{|c|c|c|c|}
\hline & $\begin{array}{l}\text { ensure accurate build-up of } \\
\text { communicative strategies in } \\
\text { the target language }\end{array}$ & & \\
\hline 8. & $\begin{array}{l}\text { Ability to recognise speech } \\
\text { tactics implemented as part of } \\
\text { communicative strategies of } \\
\text { the source text and provide for } \\
\text { their accurate representation in } \\
\text { the target language }\end{array}$ & (1) (2) (3) (4) (5) (6) (7) (8) (9) (10) & \\
\hline 9. & $\begin{array}{l}\text { Ability to analyse the stylistic } \\
\text { composition of the source text } \\
\text { and ensure adequate } \\
\text { representation of appropriate } \\
\text { stylistic means in the target } \\
\text { text }\end{array}$ & (1) (2) (3) (4) (5) (6) (7) (8) (9) (10) & \\
\hline 10. & $\begin{array}{l}\text { Other (if you feel that some } \\
\text { point has been left out from } \\
\text { the questionnaire, please, } \\
\text { specify as deemed } \\
\text { appropriate) }\end{array}$ & (1) (2) (3) (4) (5) (6) (7) (8) (9) (10) & \\
\hline
\end{tabular}

\section{Table 2. Questionnaire form used in the study}

Questionnaire form consisted of four columns: skill number, skill, level of significance, and comments. The 'Skill' column presented a list of skills constituting a part of compositional (skills No.1-3), structural-semantic (skills No.4-6), and rhetorical accuracy (skills No.7-9) of translation activity. In addition, respondents were given an opportunity to specify any other skill in their discretion (skill No.10). In order to maintain survey integrity, the questionnaire form did not register any specifications as to the nature of the skills listed (i.e. their affiliation with the compositional, structural-semantic, or rhetorical accuracy).

The 'Level of significance' column was intended as a 'check-box' column with possible ranks ranging from 1 to 10 . The respondents were advised to correlate each valuation mark only once to the appropriate skill listed (i.e. valuation mark ' 10 ', for example, could only be attributed to a single skill 1-10 once).

The 'Comments' column was introduced in the questionnaire to register respondents' justifications as to the choices made.

\section{Results}

The data collected were analysed based on statistical calculation and allowed us to make the corresponding inferences regarding the importance of each separate skill incorporated in the lingua-cultural competence for the training of student translators specialising in IBC. As the survey showed, the most important skills, as identified by the teachers, are:

- $\quad$ skill (b) of the compositional accuracy block (ability to identify linking elements in the source text and find adequate counterparts in the target language) $-89 \%$ of respondents;

- $\quad$ skill (a) of the structural-semantic accuracy block (ability to interpret cultural semantics of lexical units of the source text and deliver their meaning in the target language) $-79 \%$ of respondents; and

- $\quad$ skill (a) of the rhetorical accuracy block (ability to recognise communicative strategies used in the source language and ensure 
accurate build-up of communicative strategies in the target language) $-94 \%$ of respondents.

Based on the high degree of data consistency $(89,79$, and 94 per cent respectively), the resulting statistics was accepted as reasonably justified. The combination of the skills described accounts for the translator's professional fitness to carry out communicative activities designed to translate culturally marked meanings in the framework of IBC. The data obtained through the survey can be graphically presented as follows (Figure 2):

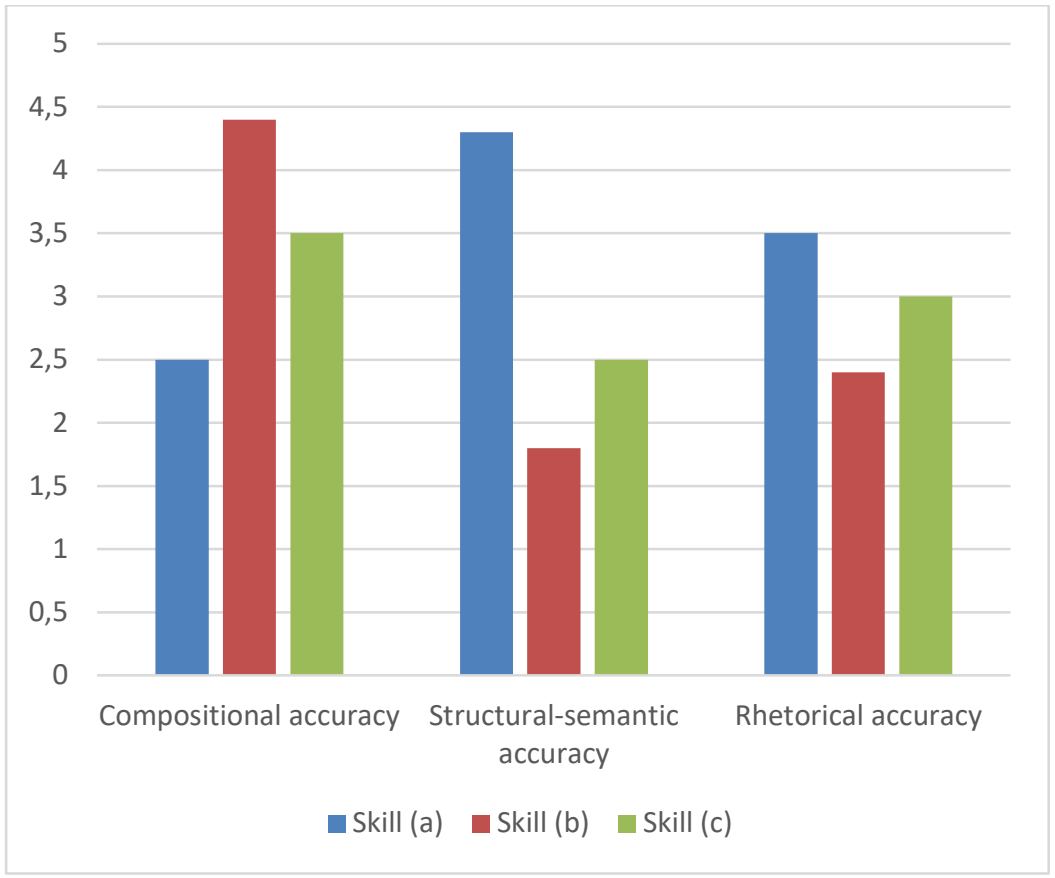

Figure 2. Ranking of skills incorporated in the compositional, structuralsemantic, and rhetorical accuracy in terms of importance for training of translators specialising in IBC

Optional part of the questionnaire (point 10 in the questionnaire form) was filled by 59 respondents, who mentioned that a translator's work in the field of IBC should be committed to acquiring knowledge about:

(1) etiquette rules of business communication (handshaking routine, cultural sensitivities, etc.):

'For example, dealing with Russians, foreign partners have to take into account that Russians consider handshaking over the threshold impolite. The etiquette of intercultural communication also embraces the so-called cultural sensitivities some topics which cannot be talked about comfortably at all, for religious, political, or other reasons' (Respondent 14, Russia).

(2) attitudes towards spatial and temporal categories:

XLinguae, Volume 11, Issue 2, April 2018, ISSN 1337-8384, eISSN 2453-711X 
'There is almost a desperation to the American feeling that time is important and urgent, whereas the British believe that it's simply courteous and efficient to arrive at the agreed hour. In Britain, ten minutes spent in small talk at the start of a meeting is not uncommon to allow attendees to relax but, in Finland and Sweden, the same will be accomplished in three minutes' (Respondent 29, UK).

(3) interpersonal proximity standards, applying to formal and informal situations of business communication:

'There are four main distances that most people observe during communication: intimate distance, personal distance, social distance and public distance. For example, for a Brit an appropriate distance from another interlocutor, a comfort zone, makes around 1.2 metres, while Russians may consider this distance somewhat large and not very comfortable for face-to-face communication' (Respondent 43, UK).

(4) cultural standards for external manifestation of feelings and emotions.

'Emotions constitute an important part of business communication. The open manifestation of negative emotions (increased tone in conversation, aggression, anger, discontent, etc.) may be regarded as indecency and not accepted' (Respondent 60, USA).

'Even smiling carries social meaning. The French, Russians and Japanese all profess to be amazed at the American and British habit of smiling for the sake of it. They smile when there's something to smile about or, in the case of people from the Far East, to hide embarrassment or to be courteous' (Respondent 76, USA).

(5) non-verbal greeting and gesturing conventions:

'The manner of the traditional greeting varies depending on the country. Understanding of barely perceptible or evident differences, as well as traditional greetings in the country, can guarantee a successful deal' (Respondent 7, Russia).

(6) peculiarities of gender relations in Eastern and Western cultures:

'It should be borne in mind that one should not allow to pay close attention to women, in some countries to stretch out a hand to greet a woman. For example, in India women mostly prefer the traditional gesture of namaste (with hands pressed together and fingers pointing upwards)' (Respondent 19, UK).

(7) psychological peculiarities of the national character:

'Interconnected combination of both emotional and rational elements makes up the psychological type of nation or national character that is manifested and reflected in the national culture, the way of thinking and acting, behavior stereotypes, determining the specificity of each nation, its difference from others' (Respondent 31, Russia).

'Psychological peculiarities are predetermined by the type of thinking, the nature of reality perception, attitude to the surrounding world, power and law' (Respondent 71, USA). 
All of these skills can be grouped as the skills of non-verbal communicative behaviour, which one of the respondents described as a 'back-up' for the general lingua-cultural competence'. These skills and ethical references form the non-verbal background of business communication and should (according to the respondents' remarks) accompany the verbal behaviour in IBC. This allowed us to make the corresponding adjustments to the model of the lingua-cultural competence that could be referred to when training translators specialising in the domain of IBC.

Thus, based on the survey conducted, in order to apply to translators specialising in IBC, the model of the lingua-cultural competence of a translator can be amended and supplemented as follows (Figure 3).

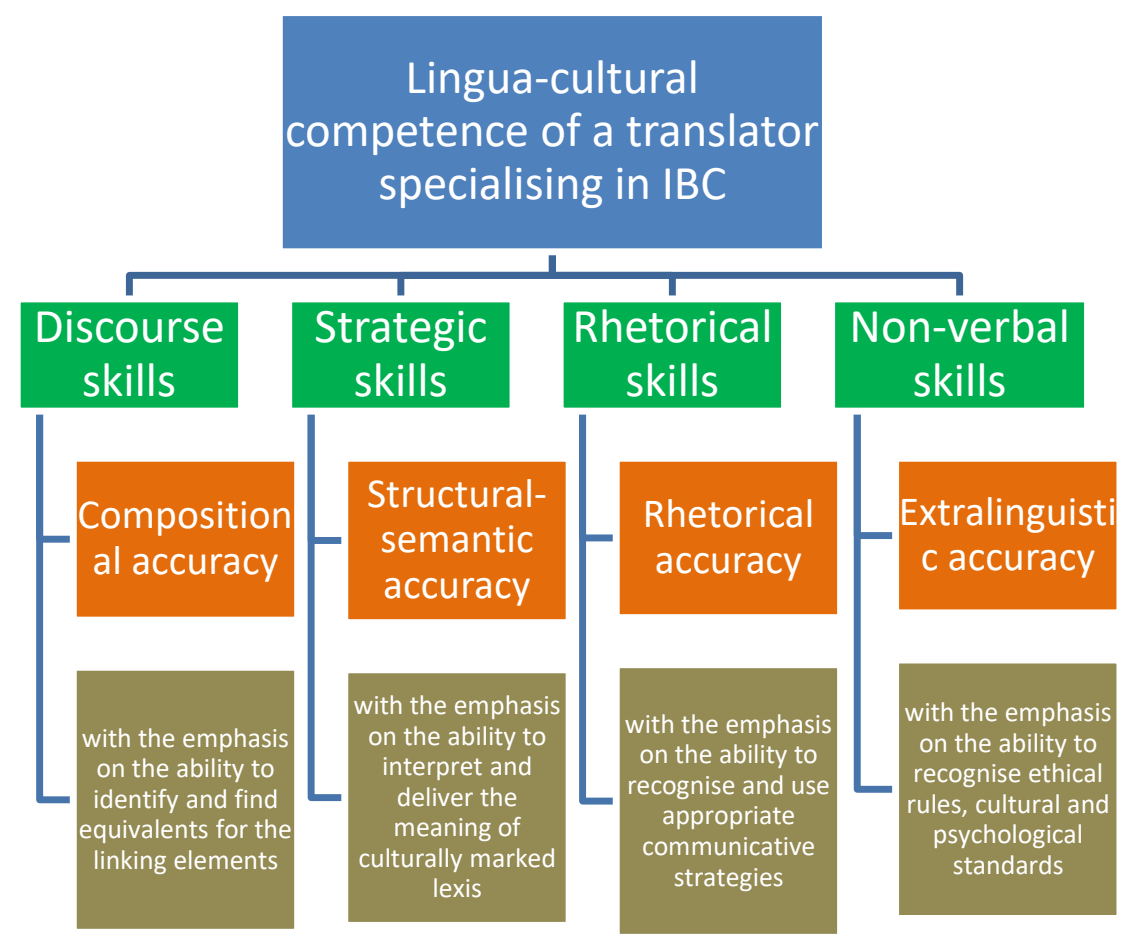

\section{FIGURE 3. The model of the lingua-cultural competence of a translator specialising in IBC}

This evidence can be further utilised to elaborate a step-by-step set of operations to help teachers proceed through a finite number of well-defined successive activities that would eventually produce a desired effect, i.e. efficient training activities capable of developing the lingua-cultural competence of student translators specialising in IBC.

\section{Discussion}

The process of translation is rather complex and contradictory in nature. According to Schweitzer (1988), its fundamental paradox can be described as 'dual loyalty', which lies in the pursuance of accuracy, on the one hand, and the translator's commitment to remain loyal to the original text, the cultural norms, and standards

XLinguae, Volume 11, Issue 2, April 2018, ISSN 1337-8384, eISSN 2453-711X 
behind it (Schweitzer, 1988). This take on the essence of translation underlies the key principles of the teaching techniques implemented to train student translators. The very notion of 'dual loyalty' implies that the translator's actions are supposed to be clearly differentiated in terms of two areas of focus. The first one involves the analysis of the original text, and the second one involves the build-up of the target text. In this study, both areas of focus were studied from the perspective of translators' lingua-cultural competence comprising the discourse (corresponding to compositional accuracy), strategic (corresponding to structural-semantic accuracy), and rhetorical (corresponding to rhetorical accuracy) skills involved.

Compositional accuracy is associated with the lexical, semantic, logical, and compositional organisation of the target text. At this level, translation is effectuated through substitution of words and a search for congruity.

Structural-semantic accuracy retains the set of semantic components, while the grammatical arrangement of the utterance changes, i.e. the semantic content of the original text is partially exhausted. This might, for example, refer to the substitution of passive voice by active voice in the target text.

At the level of rhetorical accuracy, the shifts are observed in the domains of both grammar and vocabulary. In this case, the transformations applied to alter the grammatical structure of the utterance and its lexical content should rely on the principle of linguistic selectivity, which implies that one and the same situation might be described differently by different languages.

Moving on to the methodological aspects of the second component of translators' loyalty (commitment to comply with cultural norms and standards), we note that the focus is shifted from the analysis of the original text to the construction of the target text of translation. Figuratively speaking, at this point, students are taught to turn their backs on the author of the original text and face the recipient of the target text. Essentially, this is where the focus is shifted from the rules to the underlying laws governing their application $(\mathrm{Li}, 2016)$. As a result, future translators' activity is described in terms of creativity, intuition, translation strategy, identification of relevant translation challenges, and evaluation of translation errors (Károly, 2014). At this point, greater importance may be attached to the non-verbal skills of translators specialising in IBC.

In order to address the corresponding methodological aspects and ensure efficient strategic planning of translation efforts with student translators majoring in specialised translation, the following sequence of actions can be implemented in the training process:

1. Introducing an original text containing a complete thought.

2. Establishing the semantic structure of the original text (theme and rheme).

3. Analysing the original text with a view to detect and further address translation challenges contingent upon the structural differences (segmentation, incorporation).

4. Translation proper (forming the vocabulary content of the target text, as well as its grammatical structure).

5. Taking account of linguistic and phraseological patterns of translation (literal translation, lexical / grammatical / lexical-grammatical transformation, supplementation, compression).

6. Analysing and addressing intercultural and stylistic differences.

7. Analysing and addressing register differences (formal / neutral / informal, business communication, etc.). differences.

8. Analysing and addressing lingua-cultural and sociocultural

9. Analysing and addressing extralinguistic (non-verbal) peculiarities of communication. 
Ultimately, this sequence of actions can be applied to nurture the most important sets of skills providing for the compositional, structural-semantic, rhetorical, and extralinguistic accuracy of the translation.

\section{Conclusions}

This study set out to examine the role of the lingua-cultural competence as a focal point of translators' performance aimed at accurate transfer of both linguistically and culturally marked information into the target language. By applying the survey instruments, the researchers were able to come up with the model of the lingua-cultural competence customised for the training of translators specialising in intercultural business communication.

This article firstly substantiates the argument suggesting that efficient translation implies not only mastery of the lexis and syntax of the source and target languages, but also, as pointed out by Gill and Guzmán (2011) relies on the translator's awareness of the culturally marked conventions inherent in the lingua-cultural communities using these languages. By this reasoning, the authors argue that the highpriority approach is the one setting down translation as an act of cross-language and cross-culture speech communication. From the perspective of communication models, translation is viewed as the operation of a source text in a different linguistic and cultural environment (Tonkin and Frank, 2010). This approach allows for a comprehensive explication of the concept of translation equivalence. It consists of informative elements of the original message that are subject to compulsory transfer in the course of translation. If these elements are left out, the translation loses its essence.

The content of training activities in translation studies will thus involve expanding students' linguistic and cross-cultural horizons, shaping their linguistic identity through the development of additional knowledge and skills in all the main aspects of verbal communication - linguistic, communicative, personal, and vocational. This process requires methodological grounding that would balance out the 'dual loyalty' phenomenon described by Schweitzer (1988), and highlighting translators' pursuance of both accuracy (compliance with the original text) and readability (efficient interpretation of the original text).

In light of the need for a comprehensive methodological foundation in training translators specialising in intercultural business communication, this study deployed survey instruments to come up with the model of the lingua-cultural competence customised to fit their vocational requisitions. This model was used to describe a sequence of methodological operations that could be implemented to introduce student translators specialising in intercultural business communication to the key strategies and techniques of translation. Following these recommendations, teachers will be able to teach student translators to handle translation problems associated with semantic, textual, stylistic, and cultural aspects of translation. Specifically, this refers to appreciation of the denotative, expressive, and cultural equivalence, as well as some specific differences between the source and target languages with regard to their formal coherence, the semantic unity of the text, the types, and prerequisites of cross-language congruity, and transformations introduced in the course of translation activity.

In the framework of practical application, the model suggested will help ensure future specialists' ability to: repeatedly switch from one language to another; comprehend the source text in a deeper and more profound way; correctly define translation issues, i.e. pieces of text that cannot be translated by using the method of direct linguistic and grammatical matches; depart from the original while preserving the original communicative goal to the greatest extent possible; shift from the surface to the underlying structures and vice versa; choose and properly use translation techniques; identify standard and non-standard translation issues and adopt appropriate solutions in compliance with the communicative setting; take account of intercultural differences;

XLinguae, Volume 11, Issue 2, April 2018, ISSN 1337-8384, eISSN 2453-711X 
recognise culturally marked meanings; apply non-verbal skills in translating intercultural business discourse.

The suggested methodological guidelines require application of a unified conceptual base in organising the educational process in the framework of widening educational globalization and new educational digital technologies. Using different, let alone mutually exclusive theoretical approaches in teaching practical aspects of translation, can disrupt the systemic and logical consistency of presented material and thereby have an adverse effect on the efficiency of students' learning activity.

\section{Acknowledgements}

The publication was prepared with the support of the "RUDN University Programme 5$100 "$.

\section{Bibliographic references}

BASSNETT, S. 2013. Translation studies: New accents. London, UK: Routledge.

BREUS, E. V. 2000. Peculiarities of Russian-English translation. Moscow, Russia: URAO.

CHANEY, L. H. - MARTIN, J. S. 2013. Intercultural business communication. Upper Saddle River, NJ: Pearson/Prentice Hall.

CHEN, Y. V. 2016. Translation, the knowledge economy, and crossing boundaries in contemporary education. Educational Philosophy and Theory, vol. 48, n. 12, pp. 1284-1297.

COMMAGER, H. S. 1974. The defeat of America: War, presidential power and the national character. New York, NY: Simon and Schuster.

CRYSTAL, D. 2017. My priority for the next 50 years: an online cultural dictionary. Training Language and Culture, vol. 1, n. 1, pp. 13-27.

EMERSON, M. - NOUTCHEVA, G. 2004. Europeanisation as a gravity model of democratisation. Paper presented at the conference 'Promoting Democracy and the Rule of Law: EU and US Strategies and Instruments, the Center for Democracy, Development and the Rule of Law', Stanford University, October 4-5.

GILL, R. M. - GUZMAN, M. C. 2011. Teaching translation for social awareness in Toronto. The Interpreter and Translator Trainer, vol. 5, n. 1, pp. 93-108.

HOUSE, J. 2009. Translation. Oxford, UK: Oxford University Press.

GOTTI, M. - SARCEVIC, S. 2006. Insights into specialised translation. Bern, Switzerland: Peter Lang.

KÁROLY, A. 2014. Translation in foreign language teaching: A case study from a functional perspective. Linguistics and Education, vol. 25, pp. 90-107.

KATAN, D. 2009. Translation as intercultural communication. In J. Munday (Ed.), The Routledge companion to translation studies (pp. 74-92). Abingdon, UK: Routledge.

KROUGLOV, A. 2015. Translation in a globalising world. In N. Rodriguez \& B. Schnell (Eds.), La CIUTI: Unidad en la Diversidad (pp. 75-86). Madrid, Spain: Universidad Pontifica Comillas.

LI, X. 2016. The first step to incorporate intercultural competence into a given translation curriculum: a micro-level survey of students' learning needs. The Interpreter and Translator Trainer, vol. 10, n. 3, pp. 285-303.

MAIALEN, M. L. 2017. Indirectness in literary translation: methodological possibilities. Translation Studies, vol. 10, n. 2, pp. 133-149.

MALYUGA, E. 2016. Exploiting the potential of ICT: Assessment of students' knowledge. In Proceedings of the 3rd International Multidisciplinary Scientific Conference on Social Sciences and Arts, pp. 319-326. doi: 10.5593/SGEMSOCIAL2016/B13/S03.042

MALYUGA, E. - TOMALIN, B. 2014. English professional jargon in economic discourse. Journal of Language and Literature, vol. 5, n. 4, pp. 172-181. 
MALYUGA, E. N. - PONOMARENKO, E. V. 2015. Effective ways of forming students' communicative competence in interactive independent work. In Proceedings of EDULEARN15: 7th International Conference on Education and New Learning Technologies, pp. 1397-1404.

MALYUGA E. - SHVETS, A. - TIKHOMIROV, I. 2016. Computer-based analysis of business communication language. In Proceedings of SAI Computing Conference, pp. 229-232. doi: 10.1109/SAI.2016.7555987

MILLAN, C. - BARTRINA, F. 2013. The Routledge handbook of translation studies. London, UK: Routledge.

MOLL, M. 2012. The quintessence of intercultural business communication. Berlin, Germany: Springer Science \& Business Media.

MUNDAY, J. 2012. Evaluation in translation: Critical points of translator decisionmaking. London, UK: Routledge.

PARLAKKILIC, A. 2016. Intercultural teaching through translation: An Information and Communication Technologies (ICT) literacy course case in Afghanistan. Intercultural Education, vol. 27, n. 6, pp. 587-599.

PONOMARENKO, E. V. - MALYUGA, E. N. 2015. Ironic rhetoric in Business English courses from functional linguistics perspective. In Proceedings of EDULEARN15: $7^{\text {th }}$ International Conference on Education and New Learning Technologies, pp. 1392-1396.

PYM, A. 2012. On translator ethics: Principles for mediation between cultures. Amsterdam, the Netherlands: John Benjamins Publishing.

SCHLEIERMACHER, F. D. E. 1999. Des différentes méthodes du traduire et autre texte. Paris, France: Editions du Seuil.

SCHWEITZER, A. D. 1988. Translation theory. Status, issues, aspects. Moscow, Russia: Nauka.

TOMALIN, B. 2015. Is the native speaker model dead? Issues of Applied Linguistics, vol. 1, n. 17, pp. 36-48.

TOMALIN, B. - NICKS, M. 2014. The world's business cultures and how to unlock them. London, UK: Thorogood.

TONKIN, H. - FRANK, M. E. 2010. The translator as mediator of cultures: Studies in world language problems. Amsterdam, the Netherlands: John Benjamins Publishing.

Words: 6812

Characters: 47652 (26,47 standard pages)

Full professor, D.Sc. in Linguistics, Elena N. Malyuga

Head of Foreign Languages Department, Faculty of Economics

Peoples' Friendship University of Russia (RUDN University)

117198, Moscow, 6 Miklukho Maklay Str.

Russia

malyuga_en@pfur.ru

D.Sc. in Linguistics, Alex Krouglov

Visiting Professor at Peoples' Friendship University of Russia (RUDN University)

117198, Moscow, 6 Miklukho Maklay Str.

Russia

Associate Professor in the Department of Interpreting and Translation, Guildhall

School of Business and Law

London Metropolitan University

Electra House, 84 Moorgate, London EC2M 6SQ

United Kingdom

XLinguae, Volume 11, Issue 2, April 2018, ISSN 1337-8384, eISSN 2453-711X 
krouglova@staff.londonmet.ac.uk

Barry Tomalin

Lecturer

Loughborough University

Epinal Way, Loughborough, Leicestershire, UK, LE11 3TU

United Kingdom

barrytomalin@aol.com 